\title{
Memórias de lutas e projetos políticos em disputa Entrevista com Carlos Augusto Abicalil
}

\author{
ROSELANE FÁTIMA CAMPOS* \\ Universidade Federal de Santa Catarina, Florianópolis- SC, Brasil.
}

LEDA SCHEIBE**

Universidade do Oeste de Santa Catarina, Joaçaba- SC, Brasil.

$\mathrm{E}$

m 22 de setembro de 1988, o Congresso Nacional aprovou uma Constituição para o Brasil, que acabou se tornando conhecida, nas palavras de Ulisses Guimarães, como a "Constituição Cidadã". Marco no processo de redemocratização do País, após 21 anos de ditadura civil-militar, ela estabeleceu um conjunto de direitos sociais e políticos, destacando-se a educação como direito social subjetivo. Numa conjuntura política litigada pelos atores sociais em presença, expressou as contradições do contexto histórico de seu tempo. Passadas três décadas desde sua promulgação, somos convocados, pelo presente, a interrogá-la, examinando o caminho já percorrido e, ao mesmo tempo, olhando o que ainda nos falta percorrer, em particular no governo que se avizinha.

Para nos ajudar nesse debate, convidamos o professor Carlos Augusto Abicalil. Figura conhecida no cenário político e educacional, Abicalil é licenciado em Filosofia, Sociologia e História, mestre em Educação - Gestão de Políticas Públicas - pela Universidade de Brasília. Atuou na rede pública de ensino do estado de Mato Grosso, e foi diretor e presidente da Confederação Nacional dos Trabalhadores em Educação (CNTE) entre os anos de 1993 e 2002. De 1997 a 2002 atuou também como membro do Comitê Mundial da Internacional de la Educación, e como vice-presidente da Internacional de la Educación para América Latina. Em sua trajetória política, foi deputado federal de 2003 a 2011, atuando como presidente da Comissão de Educação e Cultura, e vice-líder do Governo no Congresso Nacional. Posteriormente, foi Secretario de Articulação com os Sistemas de Educação do Ministério de Educação; Secretário Parlamentar da liderança do Governo no Congresso Nacional, e Secretário Executivo da Secretaria de Direitos

* Doutora em Educação pela Universidade Federal de Santa Catarina. É Professora Associada I da Universidade Federal de Santa Catarina, atuando no Curso de Pedagogia. Faz parte do Comitê Editorial da Revista Retratos da Escola. E-mail: <roselane.campos@ufsc.br>.

* Doutora em Educação pela Pontifícia Universidade Católica de São Paulo, é professora aposentada da UniversidadeFederal deSanta Catarina.Atualmenteé professora doPrograma dePós-graduaçãoem Educação da Universidade do Oeste de Santa Catarina e editora da Retratos da Escola. E-mail: <lscheibe@uol.com.br>. 
Humanos da Presidência de República. Atualmente mora em Madri e, desde 2015, é Diretor Geral de Educação, Ciência e Cultura da Organização de Estados Ibero-americanos.

Editoria: Professor, gostaríamos que você nos apresentasse o cenário político-nacional no período pré-Constituinte, em particular o papel dos movimentos sociais.

Carlos Abicalil: São trinta anos que marcam o mais longo período de exercício da democracia na ainda jovem república. A constituição foi produto da intensa mobilização social e popular de resistência que resultou num pacto de convivência de superação "gradual" da ditadura militar. Estas mobilizações tiveram suas origens no longo período de lutas sociais em distintas frentes - estudantil, acadêmica, sindical, política, artística, de corporações de profissionais liberais, de veículos de comunicação, de bairros, de comunidades eclesiais de base, de luta por emprego e contra a carestia, por eleições diretas etc. Esse processo resultou numa acumulação de forças que se refletiu nos resultados eleitorais da legislatura anterior ( 47ª iniciada em 1983 a 1987), mesmo que sob forte controle do último governo militar. A conjugação de forças sociais diversificadas em torno de aspirações societárias, inspiradas na perspectiva de um estado de bem estar social, ainda que sob a afirmação da economia de livre-mercado, culminou em uma agenda progressista que, dentre outros aspectos, afirmou a liberdade de pensamento, de expressão, de criação artística, de pesquisa científica, de organização e associação, a pluralidade partidária e sindical, o reconhecimento de direitos de comunidades tradicionais, $\mathrm{o}$ princípio da reparação, ainda que com os limites relativos à anistia para os crimes da ditadura. Destacamos também o fim da censura prévia. Obviamente, sob forte influência das forças de "centro" do espectro político representadas no Congresso Nacional ainda constituído sob as bases institucionais do chamado "pacote de abril de 1979". Mesmo com as limitações institucionais de uma constituinte congressual não exclusiva, tivemos avanços muito significativos na expansão dos direitos e garantias individuais e coletivos, embora permaneçam focos de tensões na consolidação de políticas públicas que visem assegurar os objetivos da República: constituir uma sociedade livre, justa e democrática.

\section{Editoria: Qual o papel dos movimentos sociais organizados em educação na conquista dos direitos sociais que figuram em nossa Constituição?}

Carlos Abicalil: Uma legitimação imprescindível e inquestionável foi o Fórum Nacional em Defesa da Escola Pública que atuou nesse cenário de mobilização anterior à Constituinte. O setor da educação, notadamente da educação pública, foi protagonista de muitas das pautas da resistência à ditadura, tanto na educação básica como na educação superior, no movimento estudantil, acadêmico e associativo (quando a sindicalização estava proibida na educação pública e ainda tutelada no setor privado). Sua dinâmica 
permitiu a realização de atividades multitudinárias, associando capacidade diagnóstica, de formulação política e de sustentação teórica, solidificando alianças que incluíram representações de gestores (notadamente nas universidades e nas administrações municipais mais progressistas) e exercendo a construção de amplos consensos progressistas entre os setores aderentes. Desde a concepção da educação como direito de todos e dever do Estado, com a consequente vinculação obrigatória de recursos, a obrigatoriedade de um plano nacional, a previsão de um sistema nacional e de um conselho nacional de educação. Isso fundamentado na afirmação da educação pública universal, gratuita, laica, de qualidade e seus princípios, a valorização profissional, a gestão democrática e a condição de afirmação da universidade fundamentada na unidade entre o ensino, a pesquisa e a extensão. O capítulo da educação na Constituição é ainda hoje uma referência internacional relevante e representa aspectos de inovação aperfeiçoados com as emendas constitucionais do período compreendido entre $2003 \mathrm{e}$ 2016, cuja inspiração estava diretamente vinculada às propostas defendidas pelo Fórum Nacional em Defesa da Escola Pública. Vale lembrar que essa capacidade do Fórum se associava a uma intensa habilidade na sistematização das suas propostas, na capacidade de articulação política com parlamentares de variada filiação partidária, desde suas bases eleitorais, na compreensão do processo legislativo, no seu monitoramento e seguimento cotidianos, na conjugação entre ação institucional, mobilização popular e comunicação social. Vale lembrar que a prática de audiências públicas na Câmara dos Deputados foi inaugurada em função dessa capacidade do Fórum, antes mesmo de estarem previstas regimentalmente ou adotadas como prática comum no trabalho parlamentar.

\section{Editoria: Em sua análise, que fatores contribuem para o que poderíamos chamar de "modernização conservadora" na educação?}

Carlos Abicalil: Vivemos numa das sociedades mais desiguais do planeta. É bem verdade que avançamos significativamente na superação da pobreza extrema desde o período constituinte, mais significativamente ainda nos primeiros 15 anos do século XXI. Viemos secularmente da cultura dominante de extermínio contra povos indígenas, da escravidão negra contra povos africanos, da exploração acelerada de recursos naturais com características devastadoras, da implantação de um modelo de inserção global submetido à monocultura de exportação na base do latifúndio, fundado na violência material e na violência simbólica. É sabido que a consolidação de direitos se faz atravessando gerações. Não chegamos a conformar um sistema nacional de educação, no sentido estrito, até agora, embora tenhamos presente e em funcionamento a maioria dos elementos. A força de um sistema nacional consiste exatamente na sua capacidade de superar desigualdades e reorientar a ação do poder público em razão desse objetivo da República. A modernização conservadora, de certo modo, reforçou 
a descentralização das responsabilidades pela oferta educacional, compensando com algum nível de transferência de recursos financeiros sem cuidar de maneira adequada e contínua de outros fatores de desigualdade econômica, social, cultural, estrutural e geracional com a centralidade articuladora necessária. As recentes políticas de ação afirmativa e de educação inclusiva, nos distintos níveis da educação e nas distintas esferas da administração, ainda não se consolidaram e enfrentam resistências políticas que recrudesceram recentemente. Provavelmente com níveis de resistência e enraizamento maiores do que no período de sua implementação uma ou duas décadas atrás. Há um combate cultural e de valores por trás e ao lado do combate das condições econômicas gerais de financiamento público estrito senso.

\section{Editoria: Atualmente, observamos no Brasil uma ascensão de movimentos "neoconservadores", cujo alvo têm sido as universidades, as escolas e os professores. De sua perspectiva, quais são as implicações desses movimentos para a educação nacional?}

Carlos Abicalil: Esse fundamentalismo neoconservador, a rigor, é o mesmo que orientou a exploração colonial desde o século XVII. Em boa medida, é anterior às conquistas da Revolução Francesa do final do século XVIII. Não chega a incorporar o Regime Republicano. Não estranha que tenha como um dos seus arautos um dos herdeiros da antiga família real que se alinhou á campanha presidencial vitoriosa em 2018. De certo modo, não incorpora nem alguns dos elementos da chamada Reforma Protestante, nos âmbitos da cultura, da religião, da ciência. O que se dirá então sobre sua distância frente ao humanismo híbrido expresso na “Declaração Universal dos Direitos do Homem", que completa meros 70 anos! Um retrocesso quase absurdo se não observamos as razões estruturais que usam a "moral" individual e os "bons" costumes como escudos para facilitar sua ocultação. O obscurantismo, a ignorância, a ausência da crítica, o autoritarismo e a tentativa de legitimar o pensamento único são os produtos mais diretos dessa empreitada. Como antes, enfrentará a resistência do movimento, desafiado a encontrar forma, método e meios de vencer a disputa cultural e de valores com a crueza e a complexidade com que se apresenta contemporaneamente.

Editoria: Uma das conquistas dos profissionais da educação com a Constituição de 1988 foi o direito à sindicalização e o direito à greve. Como isso repercutiu nas organizações coletivas deste segmento profissional?

Carlos Abicalil: A maioria dos sindicatos da educação pública básica pública surgiu nos anos 60 do século passado, no âmbito dos estados, das capitais e dos grandes municípios. Logo, sob o regime militar, foram impedidos de se estruturar como sindicatos. Continuaram suas ações como associações profissionais, já conquistando 
direitos como o de acesso ao trabalho docente na educação pública por meio de concurso público de provas e títulos, garantias de formação específica para o magistério e para as “especialidades' derivadas da formação pedagógica. Em paralelo, cresceram as formas de associação em âmbito nacional e de diversificação de representação para além do magistério, mantendo uma identidade distinta do funcionalismo público geral. Fortemente engajadas nas mobilizações civis e populares contra a carestia, por liberdade, justiça e democracia, também foram importantes no surgimento do chamado "sindicalismo autônomo" e na criação da Central Única dos Trabalhadores, ainda no período anterior à Constituinte. A garantia do direito de livre organização e associação advinda da Constituição de 1988, possibilitou a consolidação da estrutura sindical em todos os níveis, dinamizada por uma prática de organização de base anterior e uma sólida discussão interna sobre a identidade profissional mais ampla (profissionais da educação), assim como na identidade de classe trabalhadora. Não significa, contudo, que já se superou o corporativismo em definitivo, mas avançou-se muito na consciência como classe trabalhadora nesses mais de 50 anos.

\section{Editoria: Atualmente, os movimentos sociais avaliam que é necessário mudar sua estratégia de organização e mobilização junto à sociedade. Qual sua análise sobre essa questão?}

Carlos Abicalil: Hoje, estamos novamente desafiados a intensificar a organização de base e a revisitar as identidades profissionais nascidas desse último período, o que coincide com o revigoramento de posições neoconservadoras também no interior da categoria. A expansão do emprego nas redes de educação pública e privada, assim como a renovação de seus quadros profissionais, nesses últimos anos parece não ter sido acompanhada pela sindicalização de igual intensidade. Também interferem muito as formas de contratação temporária, precária e intermediada por empresas de terceirização, assim como a perspectiva de melhores condições de trabalho e remuneração em outros postos de trabalho paralelos ao exercício profissional na educação. Vale lembrar que a CNTE, por exemplo, só teve o reconhecimento efetivo como interlocutora nacional da educação pública básica na iminência da Conferência Nacional de Educação para Todos, já no período do ex-presidente Itamar Franco, sob a gestão do ex-ministro Murílio Hingel, no início da década de 1990. Esse período reconheceu uma legitimidade importante da capacidade formuladora de políticas públicas além da estrita representação corporativa ou sindical. Representou um marco importante para o debate público de propostas para a formação inicial e continuada, o currículo, a avaliação, o financiamento, a articulação interfederativa e interinstitucional, o planejamento educacional, a gestão democrática, a participação em instâncias de controle e de participação social. Vale lembrar que neste processo estavam as raízes de avanços importantes como a política nacional de 
formação, o piso salarial profissional nacional dos profissionais da educação pública básica, a profissionalização dos funcionários de escola, a extensão do conceito de funções do magistério para além da regência de classe, entre outros aspectos relevantes que eram pautas entre o período constituinte e a sanção da LDB em que vários aspectos só se voltam a afirmar 20 anos depois da apelidada Lei “Darcy Ribeiro" de Diretrizes e Bases da Educação Nacional, incluindo as emendas ao capítulo da educação no próprio texto constitucional e toda a dinâmica da Conae, até a edição do PNE de 2014.

\section{Editoria: Em sua análise, que tarefas estão colocadas para os movimentos sindicais de profissionais da educação na atual conjuntura política?}

Carlos Abicalil: Atravessamos um período de restrição de direitos desde o processo de impeachment da presidenta eleita Dilma Rousseff. Já no seu segundo governo eram fortes as pressões por "ajustes fiscais", que reduziram a capacidade de expansão da oferta pública, acelerada desde 2006/2007. Há muitas lições aprendidas nesses mais de trinta anos. Tanto no que se refere ao período do Fórum Nacional Em Defesa da Escola Pública, nos Congressos Nacionais de Educação (Coned) no seu auge e no seu desfecho, quanto na dinâmica de participação social possibilitada pelas Conferências Nacionais de Educação e no Fórum Nacional de Educação que culminaram com o Plano Nacional de Educação, sancionado em 2014. Há um novo cenário político, alterado fortemente pelo golpe, representado pelo impeachment e agravado pela recente vitória eleitoral de setores ultraconservadores e de direita radical, tanto nos parlamentos quanto nos executivos estaduais e nacional. Vale lembrar que as eleições municipais de 2016 já apontavam essa tendência, de algum modo testadas nas difusas mobilizações de 2013, com forte apoio midiático e empresarial. Por um lado, é urgente compreender bem esses fenômenos, suas razões, seus processos sociais, culturais, políticos e econômicos, sem assombros e sem reservas territoriais, quanto aos universos de atuação de cada âmbito do movimento implicado. Paralelamente, compreender que estamos noutro patamar organizativo no interior de cada organização, entidade, movimento representado, com um público diferente daquele que fez frente à segunda metade do século passado, seus métodos, idiossincrasia e seus recursos. Também reconhecer as novas formas de organização, mobilização, participação e representação que fogem do espectro já normatizado e suas tensões frente às formas já instituídas. Reconhecer as fortalezas adquiridas nessa diversidade mais ampla e identificar corretamente o que se passou no campo adversário. Apontar o legado das políticas públicas alcançadas nessa travessia, revisitar as proposições que a nutriram cujas origens estavam nas formulações dos anos 80 e 90, ressaltar suas virtudes e não descuidar de suas fragilidades. Revigorar a capacidade de diálogo, da mediação de conflitos no interior do próprio movimento de resistência, na execução de novas dinâmicas e metodologias de trabalho colaborativo e 
de mobilização de distintos níveis de abrangência popular. Fortalecer a capacidade de gerar consensos, promover ações conjuntas, formar alianças interinstitucionais, realizar uma ação comunicativa abrangente e executar uma agenda de resistência em torno da defesa da democracia e dos direitos. Saber que a batalha será longa e que o adversário também experimenta o "novo" e age com estratégia, muito além do ensaio. É luta de classe. É o capitalismo global associado a uma nova ascensão da direita. É geopolítica.

\section{Editoria: Analisando o cenário nacional, qual sua avaliação das propostas para a educação divulgadas no plano de governo da próxima Presidência da República?}

Carlos Abicalil: O campo da educação, neste sentido, goza de uma legitimidade que poucos setores compartem. Os efeitos serão previsivelmente dramáticos. O Plano Nacional de Educação está ferido de morte. As instâncias de controle social previstas em lei para seu monitoramento e avaliação já foram debilitadas no biênio 2016/2017. Mesmo a manutenção das atuais condições de oferta pública está comprometida. A cobiça privada sobre o fundo público não dá sinais de arrefecimento e, contraditoriamente, o agravamento da crise na oferta pública favorece a disseminação da percepção social positiva das iniciativas privatizantes e seletivas no primeiro momento. Daí resulta a intensificação da disputa pela percepção social da crise, da narrativa sobre suas causas e das possibilidades de sua superação. A disputa cultural sobre os valores de convivência democrática e dos objetivos da República está na ordem do dia. Daí a intencionalidade do governo eleito ao apontar para a utilização da EaD em parcela expressiva do currículo do ensino médio e da educação de jovens e adultos, o esvaziamento da capacidade crítica ao modelo liberal com a dita "escola sem partido", o controle e vigilância ideológica sobre a prática do professorado, as ameaças sobre a gestão democrática em todos os níveis, a "militarização" escolar como modelo de "educação cívica", o banimento da abordagem da temática de gênero, o controle sobre a narrativa da história nacional etc. O resultado eleitoral de 2018 também não aponta para a revogação da EC 95. O agravamento da crise fiscal e de sua percepção e difusão social é parte da estratégia de sua afirmação. As maiorias parlamentares resultantes das eleições não sinalizam disposição inicial para a revogação. Esse cenário indica mais claramente uma ação de contenção das perdas e de resistência. Como antes, resistência criativa, mobilizadora, propositiva, de largo alcance popular e de amplo espectro político no campo democrático. Setores intermediários da administração pública podem ser atores importantes na alteração dessa percepção social informada pelo resultado eleitoral. Uma importantíssima matéria de produção de conhecimento e de difusão da capacidade social de mover a história, enfrentar adversidades, aproveitar as contradições para forjar brechas que apontem horizontes expansivos de direitos e superadores de desigualdades. Uma agenda de conteúdos e significações importante para reconhecer o feito, criticá-lo, identificar limites, ressaltar possibilidades, valorizar 
sua contemporaneidade, denunciar violações, cobrar reparações, desafiar instituições. É uma ferramenta muito importante para motivar, organizar, mobilizar, convencer. Um contraponto de contraste indispensável para orientar a luta social, cultural e política. Um ponto de fragilização do confronto entre os discursos representados pelo candidato presidencial e sua carreira política, do eleito e do chefe de Estado que estará em exercício. Também desafia a lidar com as expectativas populares colhidas pelo populismo de direita na campanha e as frustrações consequentes à política real e à confirmação de um sistema para poucos e sob o controle de um Estado quase policial, como se indica nesses primeiros dias pós eleições. Não será fácil nem linear. Nunca foi. A história não acabou. Seremos muitos mais. Entretanto, será preciso também cuidar uns dos outros: "ninguém larga a mão de ninguém". Há generosidade em broto. 